\title{
The Perceived Maternal Parenting Self-Efficacy (PMP S-E) tool: The adaptation study in the context of attachment styles and mood in the first-time mothers
}

\author{
Yasemin Kahya ${ }^{10}$, Sait Uluc ${ }^{2}{ }^{(1)}$ \\ ${ }^{1}$ Social Sciences University of Ankara, Faculty of Social Sciences and Humanities, Department of Psychology, Ankara - Turkey \\ ${ }^{2}$ Hacettepe University, Faculty of Letters, Department of Psychology, Ankara - Turkey
}

\begin{abstract}
Objective: Maternal self-efficacy is defined as beliefs about one's ability to be successful in the maternal role. Studies have shown that perceived maternal self-efficacy was related to maternal depression, the perception of infant temperament, and the quality of mother-infant interactions. The purpose of this study was to conduct an adaptation study of the Turkish version of Perceived Maternal Parenting Self-Efficacy Tool (PMP S-E Tool).

Method: For this purpose, three different study samples which were composed of the first-time mothers of full-term healthy infants were reached out. The mothers in the first sample $(n=290)$ filled out the Turkish PMP S-E online for construct validity and internal consistency analyses. The mothers in the second study sample $(n=50)$ filled out the Turkish PMP S-E, the CES-Depression Scale, the State-Trait Anxiety Inventory, the Early Close Relationships-II, and the Infant Behavior Questionnaire-VSF online for criterion and predictive validity analyses. The mothers in the third study sample $(n=57)$ filled out the Turkish PMP S-E twice, post-partum pre-test at their home and 4-month post-test at the laboratory.

Results: The results of Confirmatory Factor Analysis supported the four-factor structure of the original PMP S-E. The sub-scales were Care Taking Procedures, Evoking Behaviors, Reading Behaviors, and Situational Beliefs. Internal consistency values of the Turkish PMP S-E total and sub-scales were high. The results of criterion validity and test-re-test reliability provided evidence for the Turkish PMP S-E total and sub-scale scores. Predictive validity findings demonstrated that total scores of the Turkish PMP S-E were predictive of maternal life satisfaction.

Conclusion: Findings provided support for the reliability and validity of the Turkish PMP S-E for the first time-mothers with infants between 0-12 months. The Turkish PMP S-E was considered to have both research and clinical utility.
\end{abstract}

Keywords: Infant temperament, maternal self-efficacy, maternal well-being, maternal attachment style, the first-time mothers

\section{INTRODUCTION}

Bandura (1) defined how self-efficacy perception can affect behaviors and the impact of successful or unsuccessful experiences on this perception. Teti and
Gelfand (2) examined the role of self-efficacy on parenting and made the concept of self-efficacy specific as "parental self-efficacy". Therefore, maternal selfefficacy is defined as the mother's belief in her ability to provide adequate care for her baby (2).

How to cite this article: Kahya Y, Uluc S. The Perceived Maternal Parenting Self-Efficay (PMP S-E) Tool: the adaptation study in the context of attachment styles and mood in the first-time mothers. Dusunen Adam The Journal of Psychiatry and Neurological Sciences 2021;34:50-63.

Correspondence: Yasemin Kahya, Social Sciences University of Ankara, Faculty of Social Sciences and Humanities, Department of Psychology, Ankara - Turkey

E-mail: yaseminoruclular@gmail.com

Received: June 06, 2020; Revised: October 08, 2020; Accepted: January 10, 2021 
Coleman and Karraker (3) draw attention to some propositions that are necessary for a mother to feel competent in parenthood. Firstly; the mother should have the necessary behavioral repertoire for situations that are a normal part of raising children (e.g, knowing how to calm a crying baby). In addition, the mother should be confident in her ability to make these interventions and believe that the infant will respond to her efforts. Finally, she should believe that her efforts will be supported by those around her (3). If these propositions are met, the mother is expected to have a high sense of self-efficacy.

Infants are the most prominent participants in the maternal feedback on parental competence. It is known that a crying baby stops crying in response to the mother's attempts to calm down and this experience increases the sense of maternal self-efficacy (4). There are researches in the literature on how the development of maternal self-efficacy perception progresses from the birth of the infant. In the study of Benedetto and Ingrassia (5), a longitudinal course of maternal selfefficacy was observed in the postnatal period. The findings showed that there is a significant decrease in perceived maternal self-efficacy in the third month compared to the first month after birth, and it increases to the previous level in the first month around the sixth month. Among the empirical findings in the literature, it is seen that postpartum maternal self-efficacy scores increase under normal conditions for a typical motherinfant couple (4). Although it is considered that an increase in the perceived maternal self-efficacy may be expected after the experience gained in infant care, it is also among the possible suggestions that a longitudinal linear increase may not be experienced.

Studies in the literature have shown a negative correlation between perceived maternal self-efficacy and depressive symptom level and parental stress level (6-8). For this reason, some of the studies in the field of self-efficacy focus on the relationship between maternal well-being and perceived self-efficacy. On the other hand, other studies have drawn attention to the significant correlation between the perceived maternal self-efficacy and the infant's stress (9) and the difficult temperament perception towards the baby $(10,11)$. When all empirical findings are evaluated together, the perceived maternal self-efficacy stands out as a variable that can affect both the maternal psychological wellbeing and the infant.

Other studies in the literature draw attention to the association between the perceived maternal self-efficacy sensitivity and infant development. In the study of
Leerkes and Crockenberg (9), the decrease in the maternal self-efficacy level predicted the decrease in maternal sensitivity. The study of Coleman and Karraker (12) showed that as the maternal self-efficacy increased, the cognitive development scores of the infants and their compassionate attitudes, compliance, and enthusiasm towards the mother increased. The study of Hsu and Lavelli (13) revealed a positive correlation between the perceived maternal self-efficacy level and the ability to establish careful, sensitive, and positive interactions. The study by Paris et al. (14) focusing on the increasing self-efficacy levels showed that the increase in self-efficacy improves the capacity to establish harmonious and sensitive interaction. Finally, the study of Gartstein and Iverson (15) revealed that, in addition to the positive correlation between the maternal self-efficacy level and sensitivity to mother, maternal self-efficacy predicted the secure attachment scores of 12-month-old babies.

A review of the national literature reveals that there are no published studies on a tool that can examine maternal self-efficacy for the first 12 months following the birth of the baby. It is seen that there is only one scale published in the national literature to assess the self-efficacy of parents with children aged 1-3 (16). The scope of the items in this scale is not suitable for assessing the perceived maternal self-efficacy with 0 -12-month-old babies as age range. The reason for this is that the scale was adapted to Turkish to assess the self-efficacy of parents with children aged 1-3 (16). However, it is known that parental self-efficacy should be measured according to the age and developmental period of the infant or child (17). Therefore, the Perceived Maternal Parenting Self-Efficacy (PMP S-E) Tool (18) aimed to be adapted in this study, and the aforementioned scale (16) differ according to the age range covered, and the Turkish version of PMP S-E aimed to fill the gap in the relevant field that evaluates the self-efficacy of mothers with a 0-12-month-old baby. However, it may be appropriate for researchers or practitioners who want to examine parental self-efficacy in the 0-12 and 1-3 age range to use both scales simultaneously. In addition, it is thought that the introduction of a tool assessing parental self-efficacy in the early period (0-12 months) as a construct associated with the parental psychological well-being, the quality of the interactions, and the development of the baby, will contribute to the national literature.

Therefore, the aim of this study is to adapt PMP S-E (18) to Turkish. For this purpose, the adaptation study of the PMP S-E Turkish Form was examined on three 
different study groups consisting of mothers who gave birth to their first baby. In the first study group, it was assumed that the Turkish Form of PMP S-E would have construct validity showing acceptable model fit and that the entire scale and each sub-factor would show an internal consistency of at least 0.70 . By examining the criterion validity in the second study group, the scores obtained from the PMP S-E Turkish Form, the maternal well-being (depression and anxiety level), the patterns of establishing close relationships (such as the anxious and avoidant dimensions reflecting insecure attachment), and temperament perception towards the infant (negative emotionality, positive affectivity, and regulatory capacity) were postulated to be significantly correlated. At the same time, it was assumed that the scores obtained from the PMP S-E Turkish Form would predict the maternal satisfaction of life scores. Finally, with the examination of the test-retest reliability in the third study group, it was assumed that the correlation between two-times measurements conducted with PMP S-E would indicate that the perceived maternal selfefficacy show a certain level of continuity.

\section{METHOD}

\section{Sample}

The present research sample consists of three different study groups, including mothers who gave birth to their first healthy baby. The first study group was recruited to evaluate the construct validity and internal consistency of the PMP S-E Turkish Form. The second study group was formed to evaluate the criterion and predictive validity of the PMP S-E Turkish Form. The third study group was formed to evaluate the testretest reliability of the PMP S-E Turkish Form. Within the framework of the maternal self-efficacy literature, a set of inclusion criteria valid for each study group was determined. These were having a first and only child, having a baby within the last 12 months, having a baby that is not premature (37 weeks or more), having a baby born at a normal weight (2.500 grams or above), and having a developmentally healthy baby. A total of 448 mothers participated in the first study group. However, final construct validity and internal consistency analyzes were conducted on a total of 290 mothers who met the inclusion criteria. All but one of the mothers in the first study group $(n=290)$ were married and the average age of the mothers was 29.23 $(\mathrm{SD}=3.33) .55 .5 \%$ of the mothers stated that they were university graduates and $41.4 \%$ were working fulltime. While the average age of the babies of the mothers participating in the first study group was 7.17 months ( $\mathrm{SD}=2.77$ ), $53.4 \%$ of the babies were boys and $46.6 \%$ were girls. The birth weights of the infants varied between 2.580 and $9.800 \mathrm{~kg}$.

A total of 56 mothers participated in the second study group, which was formed to examine the criterion and predictive validity of the PMP S-E Turkish Form. When the second study group was examined in terms of the above-mentioned inclusion criteria, the inclusion criteria were changed due to the insufficient number of participants. Within the scope of this change, it was decided to include infants born at or over 36 weeks and over $2 \mathrm{~kg}$ in the sample. As a result, final criterion and predictive validity analyzes were conducted on 50 participating mothers. All but one of the mothers in the second study group $(n=50)$ were married and the average age of the mothers was $27.94(\mathrm{SD}=4.17) .54 \%$ of the mothers stated that they had a university degree and $36 \%$ of them were working full-time. The average age of the babies of the mothers in the second study group was 6.27 months $(\mathrm{SD}=2.83)$ and their birth weight varied between $2 \mathrm{~kg} 330 \mathrm{gr}$ and $4 \mathrm{~kg} 100 \mathrm{gr}$. $48 \%$ of the infants were girls and $52 \%$ were boys.

A total of 57 mothers participated in the third study group formed to evaluate the test-retest reliability of the PMP S-E Turkish Form. In the first measurement, the infants were $35.86(\mathrm{SD}=6.59)$ days on average. In the second measurement, the infants were 4 months old. The average age of the mothers $(n=57)$ in the third study group was $29.61(\mathrm{SD}=3.71)$. During the research, $57.1 \%$ of all married mothers were university graduates and $65.5 \%$ stated that they were working full-time-paid jobs. $67.9 \%$ of the babies of the mothers in the third study group were boys, and the average birth weight of the babies was $3.387(\mathrm{SD}=0.28)$.

\section{Measures}

Socio-Demographic Information Form (S-DIF): It is a form prepared by the researchers who conducted the present study to evaluate socio-demographic variables such as the age, education level, employment status, and psychiatric diagnosis status of the mothers. Variables such as extraordinary life events in pregnancy, total gestational duration, birth complications, infant age, gender, birth weight, and developmental health status were questioned with S-DIF. Likewise, the maternal life satisfaction, "How satisfied are you with your life right now?" was evaluated on a 6-point Likert-type scale ( $1=$ Not at all, $6=$ Very satisfied). In all three study groups of the study, mothers in different study groups completed S-DIF. 
The Perceived Maternal Parenting Self-Efficacy (PMP S-E) Tool: The PMP S-E was developed by Barnes and Adamson-Macedo (18) within the framework of Bandura's Self-Efficacy Theory. The PMP S-E consists of 20 items rated between 1 and 4 (1=strongly disagree, $4=$ strongly agree). The original PMP S-E form consists of four sub-factors: Care Taking Procedures, Evoking Behaviors, Reading Behaviors and Situational Beliefs. In the original form, the construct validity of the scale was tested in terms of difference between mothers who had caregiving experience and mothers who had not. It was found that the PMP S-E significantly distinguished between mothers with previous childcare experience and mothers with no such experience. In addition, the Cronbach alpha internal consistency coefficient of the whole scale of PMP S-E was 0.91; internal consistency coefficients for subscales were calculated as $0.74,0.89$, 0.74 and 0.72 , respectively. Test-retest reliability coefficient calculated using Spearman rho rank correlation was 0.96 . The findings indicate that the original form of PMP S-E is a valid and reliable measurement tool (18). However, as far as is known, there is no validity and reliability study of the PMP S-E Turkish Form published in the national literature. Within the scope of this research, the Turkish Form of PMP S-E was constituted and the validity-reliability study of the PMP S-E Turkish Form was conducted.

Experiences in Close Relationships Scale-II (ECRII): The attachment patterns of the mothers in the second study group were assessed by ECR-II. The ECRII consists of a total of 36 items, 18 in the anxiety and 18 in the avoidance sub-dimensions (19). The items are answered on a 7-point Likert-type scale $(1=$ Never Agree, $7=$ Strongly Agree). The scores for each attachment dimension are calculated by taking the average of the item total score. The increase in scores indicates an increase in the anxious or avoidant attachment patterns. The adaptation study of the ECRII Turkish Form was conducted by Selcuk, Gunaydin, Sumer and Uysal (20). In the adaptation study, the Cronbach alpha internal consistency coefficient for the anxious attachment dimension was 0.86 and the testretest reliability coefficient was 0.81 . The Cronbach alpha internal consistency coefficient was 0.90 for the avoidant attachment dimension, and the test-retest reliability coefficient was 0.82 . The findings show that the ECR-II Turkish Form is valid and reliable.

CES Depression Scale (CES-D): The depressive symptom levels of mothers in the second study group were evaluated with CES-D. CES-D was developed to be used in the evaluation of depressive symptoms in nonclinical samples and consists of a total of 20 items (21). Items are answered on a 4-point Likert-type scale $(0=$ never-rarely, $3=\mathrm{a}$ lot-often $)$. The total score range that can be obtained from the scale varies between 0 and 60 . As the scores obtained from the scale increase, the level of depressive symptoms increases. The validity and reliability study of the CES-D Turkish form was conducted by Tatar and Saltukoglu (22). In the Turkish adaptation study, the Cronbach alpha internal consistency coefficient varied between 0.75 and 0.90 , and the Guttman split-half test reliability was 0.89 , and the test-retest reliability coefficient was 0.69 . In the validity and reliability study, the correlation level of the scale with the Beck Depression Inventory was 0.77 . The CES-D Turkish form could distinguish patient and nonpatient groups at a rate of $81.7 \%$ (22). The revised findings show that the CES-D Turkish Form is a valid and reliable screening tool.

State-Trait Anxiety Inventory (STAI): The anxiety symptom levels of the mothers in the second study group were evaluated using the STAI. STAI was developed by Spielberger, Gorsuch and Lueshene (23). It consists of two different scales, each consisting of 20 items, the State Anxiety Inventory (SAI) and the Trait Anxiety Inventory (TAI), each consists of 20 items. While the SAI shows the state anxiety level by aiming to measure how an individual feels under certain moments and conditions, the TAI shows the level of trait anxiety regardless of the current situation and conditions (24). Items in SAI and TAI are answered on a 4-point Likert-type scale. The total score obtained from both scales ranges from 20 to 80 points, and it is understood that as the scores increase, the level of anxiety increases. The validity and reliability study of the STAI was conducted by Oner and Le Compte (25). In the STAI adaptation study, test-retest reliability values ranged from 0.26 to 0.68 for SAI, and 0.71 to 0.86 for TAI. Kuder-Richardson reliability coefficients varied between 0.94 and 0.96 for SAI in different sample groups, and between 0.83 and 0.87 for TAI. The findings obtained show that the STAI Turkish Form is a valid and reliable measurement too.

Infant Behavior Questionnaire- Revised Very Short Form (IBQ-R VSF): The temperament characteristics of the babies of the mothers in the second study group were evaluated by IBQ-R VSF. According to parental statements, IBQ-R VSF consists of 37 items, and these are evaluated on a 7-point scale (between $1=$ never and $7=$ always) $(26,27)$. The form consists of Negative Emotionality (NE), Positive 
Affectivity (PA) and Regulatory Capacity (RC) dimensions. Consisting of 12 items in total; NE is related with the characteristics of the infant such as the level of stress and fear in the face of sadness and limitations. Consisting of 13 items in total; PA is about the infant's approach behavior, vocal responsiveness and moodiness. On the other hand, RC, which consists of 12 items, is related to characteristics such as the infant's duration of orienting and soothability. In the original study, the Cronbach's alpha internal consistency coefficient was found to be 0.78 for NE, 0.77 for PA, and 0.75 for RC (27). Test-retest reliability coefficients were determined as 0.88 for NE, 0.64 for $\mathrm{PA}$ and 0.70 for RC. These findings show that IBQ-R VSF is a sufficiently valid and reliable tool (27). However, although the articles of IBQ-R VSF have already been translated into Turkish, the validity and reliability study has not yet been published.

\section{Procedure}

The necessary ethical permission for conducting the study was obtained from Hacettepe University Ethics Committee (No: 35853172/431-3728). In the creation of the PMP S-E Turkish Form, the stages of translation of the scale into Turkish by more than one expert, evaluation of the translation suggestions with the expert opinions, and the evaluation of the agreed translation suggestions by the original author after their retranslation into the original language was followed, respectively. At the end of this process, the PMP S-E Turkish Form was created.

First, in order to examine the construct validity and internal consistency of the PMP S-E Turkish Form, the scale items were shared in social communication groups where mothers can be a member via the link established on www.surveey.com. A total of 448 mothers, whose informed consent was obtained, participated in this first stage. Then, a new link was created that includes all measurement tools (ECR-II, STAI, CES-D and IBQ-R VSF) in addition to the PMP S-E Turkish Form for criterion and predictive validity analyzes and shared with the mothers via online social networks. A total of 56 mothers, whose informed consent was obtained, participated in the second stage. In the last stage, mothers who were evaluated at home in their postpartum period as the first measurement for the testretest reliability analysis of the PMP S-E Turkish Form, and in the laboratory at the 4th month as the second measurement constituted the third study group of the study. A total of 57 mothers, whose informed consent was obtained, participated in the third study group.
After examining the participants of three different study groups consisting of mothers in line with the inclusion criteria given in the sampling section, final analyzes were made.

\section{Statistical Analysis}

Within the scope of the PMP S-E Turkish Form adaptation study, item averages, item skewness levels, item-total correlation values were calculated in the mother sample of the first study group, and Confirmatory Factor Analysis (CFA) for construct validity and Cronbach alpha analysis for reliability test reflecting internal consistency were performed. The criterion validity was examined by conducting correlation analysis and predictive validity by simple regression analysis in the sample that constitutes the second study group. In the mother sample that constitutes the third study group, the test-retest reliability was examined by correlation analysis in terms of the consistency of the scores obtained from the twotime measurements in order to provide additional evidence for the reliability of the scores obtained from the PMP S-E Turkish Form.

Before analyzing the criteria and predictive validity of the PMP S-E Turkish Form, the data were investigated in terms of univariate normality assumption. The findings of this test, which was tested with the Kolmogorov-Smirnov test before the criteria and predictive validity, showed that variables other than maternal insecure attachment patterns and infant temperament dimensions were not normally distributed (D (50) Insecure Attachment $=0.11, \mathrm{p}=0.20 ; \mathrm{D}(50)=0.10$, $\mathrm{p}=0.20$; D (50) Negative Emotionality $=0.10, \mathrm{p}=0.20$; D (50) Positive Affectivity $=0.09, \mathrm{p}=0.20 ; \mathrm{D}$ (50) Regulatory Capacity $=0.09, \mathrm{p}=0.20$ ). Thus, the correlation analysis for the criterion validity was calculated using the nonparametric Spearman Rho correlation coefficient method. The Kolmogorov-Smirnov test showed that the variables of maternal self-efficacy and life satisfaction were also not normally distributed, and the histograms of these variables indicated negative skewness. Thus a logarithmic transformation was applied to the maternal total self-efficacy and life satisfaction scores to meet the linearity assumption of the simple regression analysis. After the logarithmic transformation, it was seen that the skewness values of both variables were within the + -1 limits. DFA Mplus 7.0 package program was applied with strong maximum likelihood (MLR) method to examine the construct validity Apart from this, other analyzes were conducted with the SPSS 23.0 package program. 


\section{RESULTS}

\section{The First Study Findings}

\section{Construct Validity of PMP S-E Turkish Form}

Constituting the first study group $(\mathrm{n}=290)$ in the sample of mothers, the item parameters of the PMP S-E Turkish Form were examined and analyzed for the construct validity and reliability tests. Examinations on the item parameters of the PMP S-E showed that high item averages are high, and the items had a high level of negative skewness. It was observed that the total correlation values of the items ranged from 0.58 to 0.84 (Table 1).

The CFA findings conducted to test the construct validity showed that the four-factor structure of the PMP S-E Turkish Form in accordance with the original form was at an acceptable level $\left(\mathrm{N}=290, \chi^{2} / \mathrm{df}=3.09\right.$, $\mathrm{CFI}=0.917$, TLI $=0.904 ; \mathrm{RMSEA}=0.085, \mathrm{SRMR}=0.064$, $\mathrm{AIC}=7315.695, \mathrm{BIC}=7550.567)$ (28). Accordingly, PMP S-E Turkish Form consists of four different sub-factors: as suggested in the original study, namely Caring Taking Procedures, Evoking Behaviors, Reading Behaviors and Situational Beliefs (18). These sub-factors could be significantly loaded on the second level Maternal Selfefficacy latent variable. The factor structure, standardized factor loadings and item error variances obtained as a result of CFA are shown in Figure 1.

\section{Reliability of PMP S-E Turkish Form}

The Cronbach alpha internal consistency coefficients of the PMP S-E Turkish Form were 0.97 for the whole scale, 0.81 for the Care Taking sub-factor, 0.92 for the Evoking Behaviors sub-factor, 0.91 for the Reading Behaviors sub-factor and 0.91 for the Situational Beliefs sub-factor. In addition, the Guttman split-half test reliability coefficient of the PMP S-E Turkish Form was 0.95 .

\section{The Second Study Findings}

\section{Criterion and Predictive Validity of PMP S-E Turkish} Form

The criterion and predictive validity of the PMP S-E Turkish Form was tested in the sample of mothers $(\mathrm{n}=50)$ comprising the second study group. In this context, the correlation coefficients between the total score and sub-factor scores obtained from the PMP S-E

Table 1: Item Parameters of PMP S-E Turkish Form

\begin{tabular}{|c|c|c|c|c|c|c|c|c|}
\hline & Range & Min. & Max. & Avr. & SD & Variance & Skewness & ITC \\
\hline SE_1 & 3 & 1 & 4 & 3.67 & 0.62 & 0.39 & -2.37 & 0.81 \\
\hline SE_2 & 3 & 1 & 4 & 3.70 & 0.63 & 0.40 & -2.56 & 0.77 \\
\hline SE_3 & 3 & 1 & 4 & 3.54 & 0.68 & 0.46 & -1.71 & 0.72 \\
\hline SE_4 & 3 & 1 & 4 & 3.40 & 0.65 & 0.43 & -1.15 & 0.73 \\
\hline SE_5 & 3 & 1 & 4 & 3.65 & 0.60 & 0.36 & -2.09 & 0.78 \\
\hline SE_6 & 3 & 1 & 4 & 3.68 & 0.64 & 0.41 & -2.44 & 0.83 \\
\hline SE_7 & 3 & 1 & 4 & 3.69 & 0.66 & 0.43 & -2.48 & 0.84 \\
\hline SE_8 & 3 & 1 & 4 & 3.61 & 0.67 & 0.45 & -2.04 & 0.78 \\
\hline SE_9 & 3 & 1 & 4 & 3.52 & 0.69 & 0.47 & -1.55 & 0.78 \\
\hline SE_10 & 3 & 1 & 4 & 3.56 & 0.66 & 0.43 & -1.72 & 0.82 \\
\hline SE_11 & 3 & 1 & 4 & 3.36 & 0.77 & 0.59 & -1.18 & 0.71 \\
\hline SE_12 & 3 & 1 & 4 & 3.30 & 0.78 & 0.61 & -0.90 & 0.64 \\
\hline SE_13 & 3 & 1 & 4 & 3.47 & 0.63 & 0.40 & -1.19 & 0.76 \\
\hline SE_14 & 3 & 1 & 4 & 3.57 & 0.66 & 0.44 & -1.76 & 0.78 \\
\hline SE_15 & 3 & 1 & 4 & 3.50 & 0.72 & 0.51 & -1.60 & 0.76 \\
\hline SE_16 & 3 & 1 & 4 & 3.50 & 0.67 & 0.45 & -1.40 & 0.78 \\
\hline SE_17 & 3 & 1 & 4 & 3.54 & 0.73 & 0.53 & -1.74 & 0.66 \\
\hline SE_18 & 3 & 1 & 4 & 3.67 & 0.67 & 0.45 & -2.40 & 0.75 \\
\hline SE_19 & 3 & 1 & 4 & 3.41 & 0.80 & 0.64 & -1.28 & 0.58 \\
\hline SE_20 & 3 & 1 & 4 & 3.82 & 0.56 & 0.31 & -3.84 & 0.84 \\
\hline SE_Total & 60 & 20 & 80 & 71.15 & 10.50 & 110.198 & -2.791 & - \\
\hline
\end{tabular}




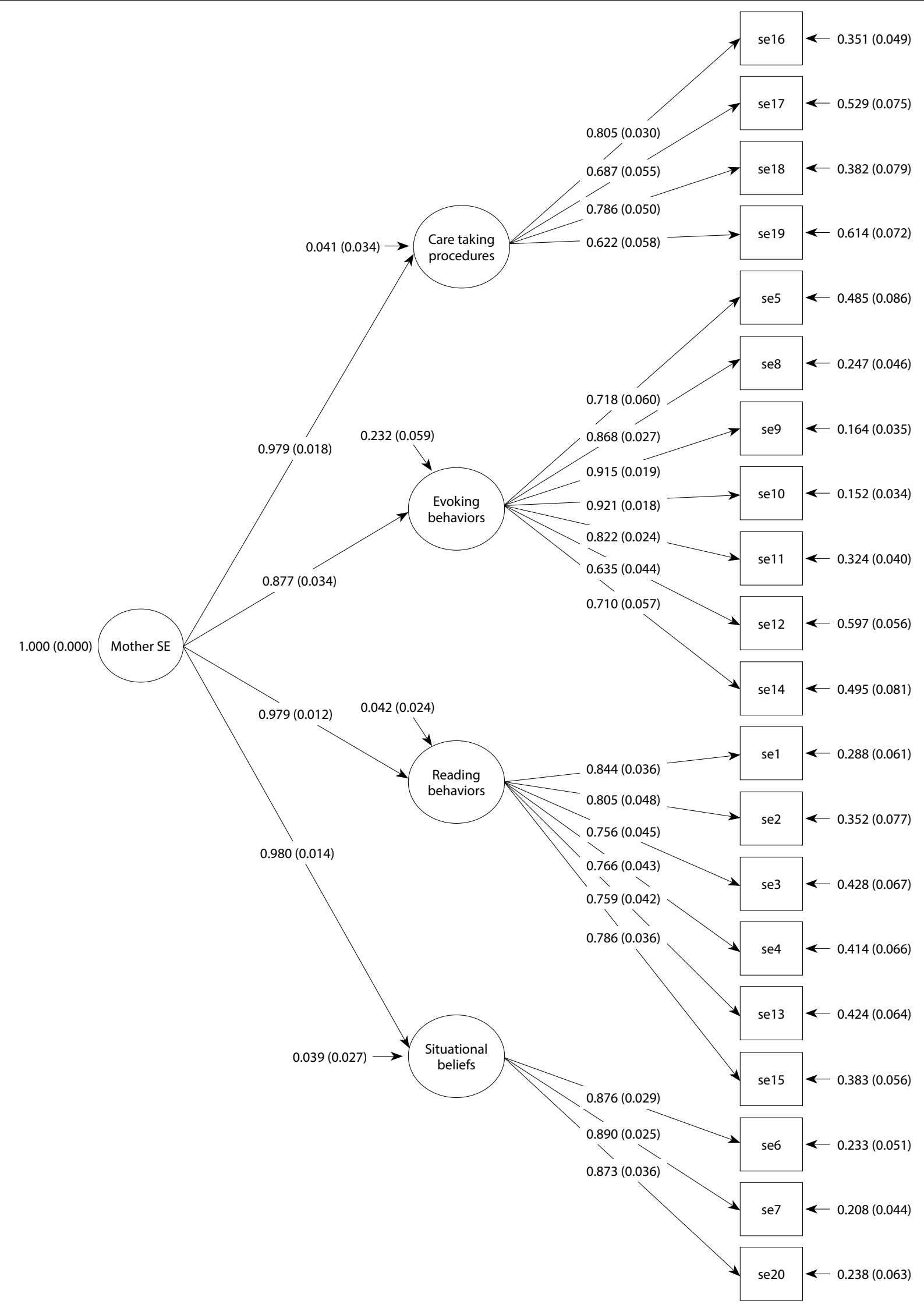

Figure 1. CFA Findings for the Construct Validity of PMP S-E Turkish Form. 
Turkish Form and the maternal insecure attachment scores, state-trait anxiety levels, depressive symptom level and infant temperament dimensions were examined.

According to the correlation findings, the total score obtained from the PMP S-E Turkish Form $(\mathrm{n}=50$, rs $=$ $0.32, \mathrm{p}<0.05)$, Care Taking Procedures $(\mathrm{n}=50, \mathrm{rs}=-0.40$, $\mathrm{p}<0.01)$, Reading Behaviors $(\mathrm{n}=50, \mathrm{rs}=-0.32, \mathrm{p}<0.05)$ and the scores obtained from Situational Beliefs sub-factors $(\mathrm{n}=50, \mathrm{rs}=-0.32, \mathrm{p}<0.05)$ and the negative correlations between the maternal avoidant attachment pattern were found to be significant. On the other hand, the maternal insecure attachment pattern was negatively marginally correlated with the PMP S-E Turkish Form Reading Behaviors sub-factor score $(n=50, r s=-0.29, p=0.045)$. These relationships within the scope of insecure attachment patterns were also examined after maternal depression and anxiety levels were checked. As a result of this examination, it was seen that only the relationship between avoidant attachment and Care Taking remained significant $(n=50$, partial $r s=-0.37, p<0.05)$.

The total score obtained from the PMP S-E Turkish Form showed marginal significance with the state anxiety $(\mathrm{n}=50, \mathrm{rs}=-0.28, \mathrm{p}=0.051)$ and trait anxiety scores $(n=50, r s=-0.25, p=0.077)$. When the PMP S-E Turkish Form sub-factors were examined, it was seen that there was a significant negative correlation between the scores of the Reading Behavior subfactors (for state anxiety; $n=50, r s=-0.32, p<0.05$; for trait anxiety $\mathrm{n}=50, \mathrm{rs}=-0.31, \mathrm{p}<0.05)$ and Situational Belief (for state anxiety; $\mathrm{n}=50, \mathrm{rs}=-0.31, \mathrm{p}<0.05$; for trait anxiety $\mathrm{n}=50, \mathrm{rs}=-0.28, \mathrm{p}=0.046)$ and state and trait anxiety scores. These correlations were quite similar after controlling for maternal depression level, and the correlation between Situational Beliefs and trait anxiety, which was only marginally significant, turned into a marginal trend $(\mathrm{p}=0.054)$. In addition, the correlation between the total and sub-factor scores obtained from the PMP S-E Turkish Form and the maternal depression scores was not statistically significant $(\mathrm{n}=50, \mathrm{rs}=0.02, \mathrm{p}=0.893)$.

The negative correlation between the total score obtained from the PMP S-E Turkish Form and the state anxiety $(\mathrm{n}=50, \mathrm{rs}=-0.28, \mathrm{p}=0.051)$ and trait anxiety scores $(\mathrm{n}=50, \mathrm{rs}=-0.25, \mathrm{p}=0.077)$ showed marginal significance. In terms of the sub-factors of the PMP S-E Turkish Form, it was observed that there were negative significant correlation between the scores obtained from the sub-factors of Reading Behaviors (for state anxiety; $n=50, r s=-0.32, p<0.05$; for trait anxiety $n=50$, $\mathrm{rs}=-0.31, \mathrm{p}<0.05$ ) and Situational Belief (for state anxiety; $\mathrm{n}=50, \mathrm{rs}=-0.31, \mathrm{p}<0.05$; for trait anxiety $\mathrm{n}=50$, $\mathrm{rs}=-0.28, \mathrm{p}=0.046)$ and state and trait anxiety scores. These correlations were quite similar after controlling for the maternal depression level, and the correlation between Situational Beliefs, which was only marginally significant, and trait anxiety turned into a marginal trend $(p=0.054)$. In addition, the correlation between the total and sub-factor scores obtained from the PMP S-E Turkish Form and the maternal depression scores was not found to be statistically significant $(n=50$, $\mathrm{rs}=0.02, \mathrm{p}=0.893$ ).

It was understood that the total and sub-factor scores obtained from PMP S-E Turkish Form were not associated with the negative emotionality temperament scores of the infant. However, the correlation scores between the total scores obtained from the PMP S-E Turkish Form and the infant's positive affectivity $(\mathrm{n}=50, \mathrm{rs}=0.35, \mathrm{p}<0.05)$ and regulatory capacity $(\mathrm{n}=50$, $\mathrm{rs}=0.49, \mathrm{p}<0.001)$ temperament scores were positively significant. The correlation between the scores obtained from the Care Taking sub-factor and the regulatory capacity temperament scores of the infant was positively correlated $(n=50, r s=0.42, p<0.01)$. In addition, it was found that there was a positive correlation between the Evoking Behavior sub-factor scores and the infant's positive affectivity $(n=50$, $\mathrm{rs}=0.39, \mathrm{p}<0.01)$ and regulatory capacity temperament scores $(n=50, r s=0.50, p<0.001)$. The Reading Behavior sub-factor scores were positively correlated with the infant's regulatory capacity temperament scores $(n=50$, $\mathrm{rs}=0.39, \mathrm{p}<0.01$ ). Finally, Situational Beliefs sub-factor scores were positively correlated with the infant's positive affectivity temperament scores $(n=50, r s=0.30$, $\mathrm{p}<0.05$ ). The correlations mentioned in the context of the infant temperament were also examined after controlling the maternal depression and anxiety level. The partial correlation between the temperament dimensions of positive affectivity, regulatory capacity and self-efficacy were largely similar. Correlation findings, including partial correlations, are summarized in Table 2.

In order to evaluate the predictive validity of the PMP S-E Turkish Form, a simple regression analysis was conducted, in which the maternal self-efficacy total scores were the predictive variable and the maternal life satisfaction scores were the dependent variable. The following simple regression analysis results showed that the perceived maternal self-efficacy significantly predicted the maternal life satisfaction scores $(=0.32, \mathrm{t}$ $[48]=2.35, \mathrm{p}<0.05)$ and explained $10 \%$ of the variance in the maternal life satisfaction scores. 


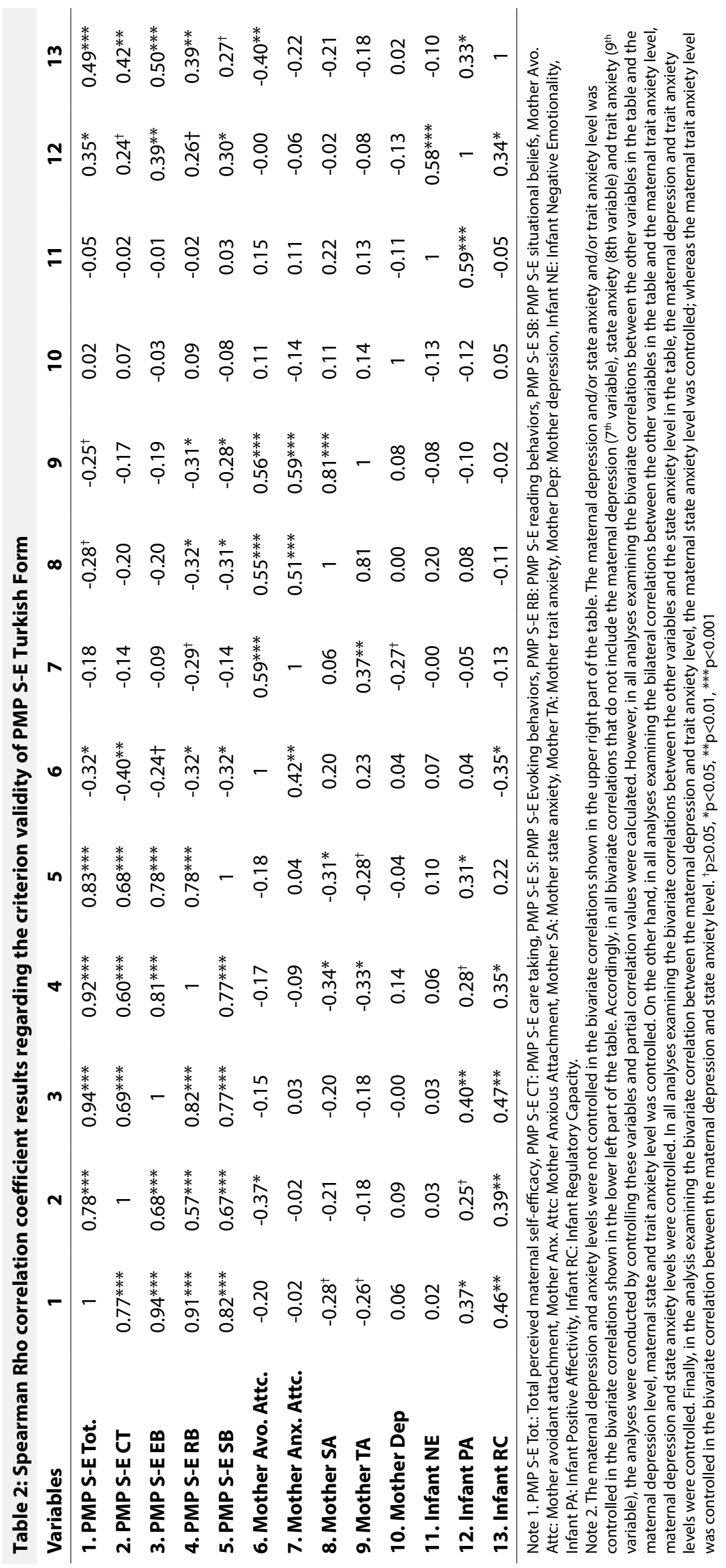

The Third Study Findings

Test-Retest Reliability of PMP S-E Turkish Form

Analyzes regarding the test-retest reliability of the PMP S-E Turkish Form were examined in the mother sample $(n=57)$ that constituted the third study group. According to the Spearman Rho correlation coefficient findings obtained from the two-time assessments, the correlation between the total scores of PMP S-E in postpartum and at four month was 0.62. The correlation between postpartum Care Taking and fourmonth Care Taking scores was 0.60 . The correlation between postpartum Evoking Behaviors and four-month Evoking Behaviors scores was 0.62. The correlation between the postpartum Reading Behaviors and four-month Reading Behaviors scores was 0.46 , and lastly, the correlation between postpartum Situational Beliefs and four-month Situational Beliefs scores was 0.51.

\section{DISCUSSION}

This study shows that the PMP S-E Turkish Form is a valid and reliable assessment tool to evaluate maternal self-efficacy especially in the first year. Construct validity, internal consistency, and test-retest findings show that the four-factor structure in the original study is also valid and reliable for the Turkish Form of PMP S-E (18). Accordingly, the construct validity findings indicate acceptable fit indices for the four-factor structure examined by CFA in the original study (28), and the internal consistency levels of all sub-factors are above 0.70 . The four-factor structure, which fits perfectly to the original PMP S-E form, has also been confirmed in Italian, Spanish and Brazilian samples (18,29-31). However, some changes were made in the item distribution of the four- 
factor structure in the Italian sample due to the sampling features (29). In the original PMP S-E study, Cronbach alpha internal consistency values were 0.91 for the whole scale, while Cronbach alpha values for sub-factors varied between 0.72 and 0.74 (18). The internal consistency values of the Turkish Form of PMP S-E indicated higher values for the whole scale and sub-factors. The larger sample size of the this study compared to the original study may be explanatory for these findings. The higher Cronbach alpha values compared to the original form showed similarities with the Spanish Form of PMP S-E (30). On the other hand, test-retest values in the original study ranged from 0.96 for the entire scale to 0.88 and 0.92 for sub-factors (18). In this context, although this study points to lower test-retest reliability values, the time difference between the two measurements is an important explanation for this situation.

Whereas in the original study had a 1-week time interval between the two measurements, this study examined the consistency of measurements over a 4-month period. In addition, the test-retest values in this study are similar to the Italian PMP S-E Form (29). As a matter of fact, the test-retest values in this study adequately support that the maternal perceived self-efficacy is a perception that varies with time and experience (1), but still shows a certain level of continuity. In addition, the original study showed that the maternal self-efficacy with more than one child was higher than mothers with one child (18). However, in this version, mothers who participated in all three study groups just had their first baby. From this point of view, examining the number of children that parents have as a variable may contribute to future studies using the PMP S-E Turkish Form.

The findings obtained from the criterion validity show that the total and sub-factor scores of the PMP S-E Turkish Form are correlated with different respects with the variables that provide evidence for the criterion validity. This pattern appears to be compatible with the dimension-specific conceptualization of self-efficacy. Dimension-specific conceptualization implies that a general perception of self-efficacy is formed by the combination of various dimensions (9). In accordance with the original PMP S-E Form, the Turkish form consists of dimensions such as Care Taking, Reading Behaviors, Evoking Behaviors and Situational Beliefs. These dimensions are significantly associated to each other and to the general self-efficacy structure.

The criterion validity findings showed the association between the increase in the avoidant attachment scores of the mothers and the decrease in the general and specific self-efficacy scores in various dimensions (Care Taking Procedures, Reading Behaviors, and Situational Beliefs dimensions). However, when the relationship between perceived selfefficacy and avoidant attachment was examined after controlling for maternal depression, state anxiety, and trait anxiety levels, the relationship between the increase in avoidant attachment scores and the decrease in only Care Taking scores remained significant. Therefore, after controlling the level of depression and anxiety, avoidant mothers may not have difficulties in their general self-efficacy perceptions regarding parenting, reading messages from their babies, evoking behaviors their babies, and some situational self-efficacy perceptions. The perception of inadequate self-efficacy in the caregiving dimension of avoidant attachment mothers can be explained by the low involvement of avoidant mothers in parenting tasks. As a matter of fact, avoidant mothers are characterized by defensive and distancing tendencies towards parenthood (32). One of the propositions that increases the self-efficacy perception is the active involvement of parents in tasks in the relevant domain $(1,3)$. Therefore, the perception of low caregiving of avoidant mothers may be due to their inability to gain sufficient experience due to possibilities such as low involvement in parenting tasks. The present study is cross-sectional. Therefore, it is worth noting that the association between the increase in the maternal avoidant attachment and the decrease in the perception of caregiving may also be in the opposite direction. Therefore, it can be argued that mothers who experienced a decrease in their caregiving perception may have also reported more avoidant attachment patterns.

While the increase in anxious attachment scores was associated only marginally with the decrease in the Reading Behaviors sub-factor scores of PMP S-E, this marginal trend becomes insignificant when the maternal depression and anxiety level was controlled. Therefore, no significant relationship was found between anxious attachment and the perceived maternal self-efficacy evaluated in this study. It is known that mothers with anxious attachment pattern have sufficient skills and qualifications to provide effective care (32) and thus their involvement in parenting behaviors may be high. For this reason, there may not be a decrease in the parental perception of mothers with anxious attachment pattern. In the literature, the association between perceived maternal self-efficacy and attachment patterns has been examined with a limited 
number of studies, and it has been stated that there are both significant direct and indirect relationships between the perceived maternal self-efficacy and insecure attachment patterns $(33,34)$. On the other hand, the lack of a significant relationship between anxious attachment and self-efficacy can be explained by the insufficient sample size of the second study group. Therefore, it is thought that examining the association between maternal attachment patterns and self-efficacy in future studies in which the sample size is expanded may fill the gap in the literature.

The increase in the state and trait anxiety scores was associated with the marginal decrease in the PMP $S$-E total score and the significant decrease in the Situational Beliefs sub-factor scores. After controlling for maternal depression levels, these relationships showed similar patterns, but the negative correlation between Situational Beliefs and trait anxiety pointed to a marginal significance. To summarize, after controlling for the maternal depression level, the increase in the state and trait anxiety scores was particularly associated with the decrease in the Reading Behaviors sub-factor scores; the increase in the state anxiety score was associated with the decrease in the Situational Beliefs sub-factor scores. It is thought that the self-efficacy perception, which reflects the status of interactions such as "I believe that my baby responds well to me.", "I show compassion to my baby", is expected to be affected by maternal state anxiety level. On the other hand, it is arguable that anxious mothers may perceive themselves inadequate in the dimension of Reading Behaviors due to their overfocus on parenting and performance concerns. Indeed, it is stated in the literature that anxious mothers have increased level personal stress, and therefore they can relate with their internal focus instead of focusing on the needs of others due to the limitations in their internal and interpersonal skills (35). Therefore, it can be argued that anxious mothers, who focus on anxiety and self-regulation, may evaluate more negatively their ability to receive messages that will develop by focusing on the needs of the baby. The Reading Behaviors can actually be considered as the mother's understanding what the baby wants with the best guess and responding to the infant in this direction. Thus, the usual predictive uncertainty in responding to messages from infants may explain that anxious mothers may have certain difficulties in receiving messages. On the other hand, it can be thought that the association between the level of anxiety symptoms and Reading Behavior scores may be in the opposite direction. It can be argued that mothers who perceive a decrease in self-efficacy in the Reading Behaviors dimension may report higher levels of anxiety symptom with this perception effect. Longitudinal studies in this field will be more enlightening in terms of the direction of the relations.

In this study, it is observed that the level of depressive symptoms is not associated with the total self-efficacy and sub-factor scores. The insignificance of the association between the self-efficacy level perceived by mothers and the level of depressive symptoms seems inconsistent with the literature (8). The Italian Form of PMP S-E was also found to be associated with lower levels of depression and stress (29). The sample size of the criterion validity in this study is quite limited. Therefore, the insufficient variance in maternal depressive symptom level may be an explanation for the findings. An empirical study indicated the moderator role of emotional support in the relationship between postpartum depression and maternal self-efficacy (33). Therefore, the correlation between maternal selfefficacy level and depressive symptom level can be examined under the influence of mediator and moderator variables in larger samples. It is known that the literature on the relationship between parental selfefficacy and psychological well-being of parents focuses more on depression (36). Current findings reveal that the maternal state and trait anxiety symptoms are associated with various dimensions of self-efficacy. Therefore, it is thought that it will contribute to the literature in future studies that plan to use the PMP S-E Turkish Form, which will focus on the anxiety symptom levels as well as the depressive symptom levels of the parents.

When the relationships between the temperament dimensions of the baby and the perceived maternal self-efficacy are examined; it is understood that there is an association between the increase in the infant positive affectivity and regulatory capacity temperament traits and the increase in maternal selfefficacy as a general dimension and all the sub-factor scores of self-efficacy. These relationships showed a similar significance after controlling for maternal depression and anxiety levels, only the relationship between the situational beliefs sub-factor scores and the infant's regulatory capacity temperament scores turned into a marginal trend. Existing relationships indicate medium-high significance. On the other hand, no significant relationship was found between the infant's temperament evaluations in the negative emotionality dimension and the perceived maternal 
self-efficacy. Therefore, it can be argued that instead of difficult temperament traits of the infant, the easy temperament traits may be related to the perceived maternal self-efficacy. Although the findings are compatible with the literature $(10,11,15)$, longitudinal studies are needed to examine the bidirectional relationships, in which the effect goes from infant to mother, and from mother to infant. To clarify, mothers with high self-efficacy may perceive their babies as more extraverted and more regulated. Although there seems to be a relationship between the infant's positive temperament traits and the perceived maternal selfefficacy, it is important to note that this study is limited to make a clear judgment about the direction of the relationship.

When examined as a general dimension, it is seen that perceived maternal self-efficacy has the predictive power of maternal life satisfaction scores. This finding can be considered as expected; parenting is a powerful experience that affects mothers' lives in many ways. Considering the temperament and maternal life satisfaction findings together, it is seen that self-efficacy measured by PMP S-E may be related to positive characteristics of the infant and positive outcome variables in the mother's life.

As a result, together with the relationships examined in different samples within the scope of this study, it is understood that the PMP S-E Turkish Form is a valid and reliable tool for mothers with a $0-12$ months old babies. Therefore, this study introduced the Turkish Form PMP S-E, which was adapted to Italian, Spanish, Brazilian and Iranian samples, and which generally indicated similar findings in different cultures and has internationally validity, to national literature (29-31,37). However, the findings point to some suggestions for future studies that will use the PMP S-E Turkish Form. In this study, in accordance with the original form, PMP S-E items were evaluated in a 4-point Likert type scale. As indicated by the high item averages, narrow item variances and high skewness values obtained as a result of the studies in the first study group, it is recommended to use the PMP S-E Turkish Form in a 7-point Likert type scale in future studies. Thus, this may be a solution against the tendency of mothers to evaluate themselves against the tendency of mothers to evaluate themselves at a high level in self-efficacy, a phenomenon that also appeared in the original study of PMP S-E $(18,36)$.

It is thought that there is a need to examine the developmental course of maternal self-efficacy. It is considered that further studies using PMP S-E Turkish
Form will be informative to measure the perceived maternal self-efficacy month by month after the birth of the infant (17). With such a research design, one can investigate which longitudinal outcome mother-infant variables would be predicted by different time assessments of maternal self-efficacy. On the other hand, it is recommended to examine the developmentalclinical model of the maternal self-efficacy. Research also showed the negative impacts of early trauma on maternal self-efficacy (33). Therefore, it is considered that studies to be conducted with PMP S-E Turkish Form in clinical sample of mothers whose past traumatic experiences are predicted to be higher may be beneficial within the scope of research and practice. Finally, in this present study, the validity and reliability of the PMP S-E Turkish Form was examined in the samples of mothers. It is thought that future studies will contribute to the validity and reliability of the PMP S-E Turkish Form in father samples. It can be stated that the PMP S-E Turkish Form is a useful tool for early prevention and intervention as a tool that can follow the maternal selfefficacy level in healthy follow-up clinics in the year after birth. Directing mothers with low self-efficacy to the early prevention and intervention processes as protective steps for the well-being of the mother and the development of the infant are among the suggestions for the clinical practice.

\begin{tabular}{|c|c|c|}
\hline \multicolumn{2}{|c|}{ Contribution Categories } & \multirow{2}{*}{\begin{tabular}{|l} 
Author Initials \\
Y.K., S.U. \\
\end{tabular}} \\
\hline \multirow{3}{*}{ Category 1} & Concept/Design & \\
\hline & Data acquisition & Y.K. \\
\hline & Data analysis/Interpretation & Y.K., S.U. \\
\hline \multirow{2}{*}{ Category 2} & Drafting manuscript & Y.K. \\
\hline & Critical revision of manuscript & S.U. \\
\hline Category 3 & Final approval and accountability & Y.K., S.U. \\
\hline \multirow{2}{*}{ Other } & Technical or material support & Y.K., S.U. \\
\hline & Supervision & S.U. \\
\hline
\end{tabular}

Acknowledgement: This study includes a part of the dissertation that the responsible author conducted under the supervision of Assoc. Dr. Sait Uluc. We would like to thank all the expert psychologists who took part in the translation and back-translation process in the creation of the PMP S-E Turkish Form. The findings of this study were presented at the European Congress of Psychology 2019, in Moscow, Russia.

Ethics Committee Approval: The necessary ethical permission for conducting the study was obtained from Hacettepe University Ethics Committee (No: 35853172/431-3728).

Informed Consent: Informed consents were obtained from participants.

Peer-review: Externally peer-reviewed. 
Conflict of Interest: Authors declared no conflicts of interest.

Financial Disclosure: Data of current research was collected during a mother-infant interaction research project supported by Hacettepe University Scientific Research Projects Coordination Unit [SHD2017-13159] and The Scientific and Technological Research Council of Turkey, Science Fellowships and Grant Programs [53325897115.02-170549].

\section{REFERENCES}

1. Bandura A. Self-efficacy: Toward a unifying theory of behavioral change. Adv Behav Res Ther 1978; 1:139-161.

2. Teti DM, Gelfand DM. Behavioral competence among mothers of infants in the first year: the mediational role of maternal selfefficacy. Child Dev 1991; 62:918-929.

3. Coleman PK, Karraker KH. Self-efficacy and parenting quality: Findings and future applications. Dev Rev 1997; 18:47-85.

4. Troutman B, Moran TE, Arndt S, Johnson RF, Chmielewski M. Development of parenting self-efficacy in mothers of infants with high negative emotionality. Infant Ment Health J 2012; 33:45-54.

5. Benedetto L, Massimo I. Parental self-efficacy in promoting children care and parenting quality: In Benedetto L, Massimo I (editors). Empirical Advances and Intervention Resources. Rijeka: IntechOpen, 2018, 31-58.

6. Bolten MI, Fink NS, Stadler C. Maternal self-efficacy reduces the impact of prenatal stress on infant's crying behavior. J Pediatr 2012; 161:104-109.

7. Leahy-Warren P, McCarthy G, Corcoran P. First-time mothers: social support, maternal parental self-efficacy and postnatal depression. J Clin Nurs 2012; 21:388-397.

8. Takács L, Smolík F, Putnam S. Assessing longitudinal pathways between maternal depressive symptoms, parenting self-esteem and infant temperament. PLoS One 2019; 14:e0220633.

9. Leerkes EM, Crockenberg SC. The development of maternal self-efficacy and its impact on maternal behavior. Infancy 2002; 3:227-247.

10. Fulton JM, Mastergeorge AM, Steele JS, Hansen RL. Maternal perceptions of the infant: Relationship to maternal self-efficacy during the first six weeks' postpartum. Infant Ment Health J 2012; 33:329-338.

11. Zheng X, Morrell J, Watts K. A quantitative longitudinal study to explore factors which influence maternal self-efficacy among Chinese primiparous women during the initial postpartum period. Midwifery 2018; 59:39-46.

12. Coleman PK, Karraker KH. Maternal self-efficacy beliefs, competence in parenting, and toddlers' behavior and developmental status. Infant Ment Health J 2003; 24:126-148.

13. Hsu HC, Lavelli M. Perceived and observed parenting behavior in American and Italian first-time mothers across the first 3 months. Infant Behav Dev 2005; 28:503-518.

14. Paris R, Bolton RE, Spielman E. Evaluating a home-based dyadic intervention: Changes in postpartum depression, maternal perceptions, and mother-infant interactions. Infant Ment Health J 2011; 32:319-338.

15. Gartstein MA, Iverson S. Attachment security: The role of infant, maternal, and contextual factors. Int J Psychol Psychol Ther 2014; 14:261-276.

16. Elibol F, Magden D, Alpar R. Validity and reliability of the selfefficacy for Parenting Task Index Toddler Scale. Bull Community Med 2007; 26:25-31. (Turkish)

17. Pierce T, Boivin M, Frenette E, Forget-Dubois N, Dionne G, Tremblay RE. Maternal self-efficacy and hostile-reactive parenting from infancy to toddlerhood. Infant Behav Dev 2010; $33: 149-158$

18. Barnes CR, Adamson-Macedo EN. Perceived Maternal Parenting Self-Efficacy (PMP S-E) tool: development and validation with mothers of hospitalized preterm neonates. J Adv Nurs 2007; 60:550-560.

19. Fraley RC, Waller NG, Brennan KA. An item response theory analysis of self-report measures of adult attachment. J Pers Soc Psychol 2000; 78:350-365.

20. Selcuk E, Gunaydin G, Sumer N, Uysal A. A new scale developed to measure adult attachment dimensions: Experiences in Close Relationships- Revised (ECR-R)- Psychometric evaluation in a Turkish sample. Turk Psychol Artic 2005; 8:1-11. (Turkish)

21. Radloff LS. The CES-D scale a self-report depression scale for research in the general population. Appl Psychol Meas 1977; 1:385-401.

22. Tatar A, Saltukoglu G. The adaptation of the CES-Depression Scale into Turkish through the use of confirmatory factor analysis and item response theory and the examination of psychometric characteristics. Bulletin of Clinical Psychopharmacology 2010; 20:213-227.

23. Spielberger CD, Gorsuch RL, Lushene RE. Manual for State-Trait Anxiety Inventory. California: Consulting Psychologist Press; 1970.

24. Aydemir O, Koroglu E. Clinical Scales in Psychiatry. Ankara: HYB Basim Yayin; 2012. (Turkish)

25. Oner N, Le Compte A. Handbook of State-Trait Anxiety Inventory. Istanbul: Bogazici University; 1985.

26. Gartstein MA, Rothbart MK. Studying infant temperament via the revised infant behavior questionnaire. Infant Behav Dev $2003 ; 26: 64-86$.

27. Putnam SP, Helbig AL, Gartstein MA, Rothbart MK, Leerkes E. Development and assessment of short and very short forms of the infant behavior questionnaire-revised. J Pers Assess 2014; 96:445458.

28. Hu LT, Bentler PM. Cutoff criteria for fit indexes in covariance structure analysis: Conventional criteria versus new alternatives. Struct Equ Model 1999; 6:1-55.

29. Pedrini L, Ferrari C, Ghilardi A. Psychometric properties of the Italian Perceived Maternal Parenting Self-Efficacy (PMP S-E). J Clin Psychol Med Settings 2019; 26:173-182.

30. Vargas-Porras C, Roa-Díaz ZM, Barnes C, Adamson-Macedo EN, Ferré-Grau C, De Molina-Fernández MI. Psychometric 
properties of the Spanish version of the Perceived Maternal Parenting Self-efficacy (PMP S-E) tool for primiparous women. Matern Child Health J 2020; 24:537-545.

31. Tristão RM, Neiva ER, Barnes CR, Adamson-Macedo E. Validation of the scale of perceived self-efficacy of maternal parenting in Brazilian sample. J Hum Growth Dev 2015; 25:277286.

32. Mikulincer M, Shaver PR. Attachment in adulthood: structure, dynamics, and change. New York: Guilford Press; 2007.

33. Brazeau N, Reisz S, Jacobvitz D, George C. Understanding the connection between attachment trauma and maternal self-efficacy in depressed mothers. Infant Ment Health J 2018; 39:30-43.
34. Kohlhoff J, Barnett B. Parenting self-efficacy: Links with maternal depression, infant behaviour and adult attachment. Early Hum Dev 2013; 89:249-256.

35. Drake KL, Ginsburg GS. Parenting practices of anxious and nonanxious mothers: a multi-method multi-informant approach. Child Fam Behav Ther 2011; 33:299-321.

36. Jones TL, Prinz RJ. Potential roles of parental self-efficacy in parent and child adjustment: a review. Clin Psychol Rev 2005; 25:341-363.

37. Aliabadi F, Borimnejad L, Kamali M, Rassafiani M, Nazi S. Perceived Maternal Parenting Self-Efficacy (PMP SE) tool: translation and face validation with Iranian mothers of hospitalized preterm neonates. Iran Rehabil J 2013; 11:7-10. 